\title{
Prolonged QT interval and cardiac arrhythmias in two neonates: sudden infant death syndrome in one case
}

\author{
D. P. SOUTHALl, W. A. ARROWSMith, J. R. OAKLEY, G. MCENERY, R. H. ANDERSON, \\ AND E. A. SHINEBOURNE
}

Cardiothoracic Institute, and Whipps' Cross Hospital, London, Doncaster Hospital, Yorkshire, and Department of Health

SUMMARY Two neonates with arrhythmias and the long QT syndrome are described. The arrhythmias were detected in utero and both infants were apparently well after birth. The first infant, although well, had a bradycardia for the first 9 days of life. A normal heart rate was documented at 10 days but a prolonged QT interval was not appreciated on the ECG. He was discharged from hospital but died suddenly and unexpectedly 3 days later. A post-mortem examination failed to find a cause for his death which therefore fell into the category of the sudden infant death syndrome (SIDS). A retrospective analysis of the perinatal electrocardiogram showed a probable junctional rhythm with 2:1 conduction to the ventricle; the QT interval was prolonged at 0.52 seconds $(\mathrm{QTC}=0.63)$. The second infant had a QT interval of 0.52 seconds $(Q T C=0.54)$ and frequent ventricular premature beats on a 24-hour electrocardiogram. She was treated with propranolol and remains well 2 years later. Sudden infant death has often been described in the siblings of children with the long QT syndrome and one other report described a case of SIDS which was said to have had a prolonged QT interval on the perinatal ECG. This report, however, provides unquestionable evidence, in one case, of an association between the long QT syndrome and SIDS.

Cardiac arrhythmias occur frequently in the healthy newborn infant (Morgan and Guntheroth, 1965; Southall et al., 1976, 1977; Ferrer et al., 1977). Some of these arrhythmias may be considered a normal finding in the newborn, but others have more serious implications as similar disorders have been reported to cause sudden death in childhood (Radford et al., 1977). With other authors (Guntheroth, 1977), we have already suggested a possible link between the more serious of the arrhythmias and conduction disorders and the sudden infant death syndrome (SIDS). We describe here two apparently healthy neonates with arrhythmias and the long QT

Cardiothoracic Institute, London

D. P. SOUTHALL, lecturer in paediatrics

R. H. ANDERSON, Joseph Levy reader in paediatrics

Doncaster Hospital, Yorkshire

W. A. ARROWSMITH, consultant paediatrician

Department of Health,

J. R. OAKLEY, clinical coordinator postneonatal mortality study Whipp's Cross Hospital, London

G. MCENERY, consultant paediatrician

Brompton Hospital, London

E. A. SHINEBOURNE, consultant paediatric cardiologist syndrome. One was treated and remains well, while the other-whose death fell into the category of SIDS-was found to have this abnormality on retrospective analysis of the electrocardiogram.

\section{Case 1}

This boy, birthweight $2.5 \mathrm{~kg}$, was the first child of a 23-year old woman. She did not smoke, and her home circumstances were materially good. At 37 weeks' gestation she was admitted to hospital with moderate pre-eclamptic toxaemia and treated with frusemide $40 \mathrm{mg}$ once daily, slow K $600 \mathrm{mg}$ twice a day, and diazepam $5 \mathrm{mg}$ three times a day. During this admission the fetal heart rate was noticed to be irregular, with slowing to less than 100 per minute. At 39 weeks' gestation spontaneous onset of labour occurred, and after 9 hours a forceps delivery was carried out for pre-eclamptic toxaemia and fetal bradycardia. The pulse rate was $140 / \mathrm{min}$ at birth but fell to $73 / \mathrm{min}$ after 12 hours. The infant was clinically well and an ECG was taken and interpreted as 2:1 atrioventricular block (Fig. 1). This brady- 
Lead 1

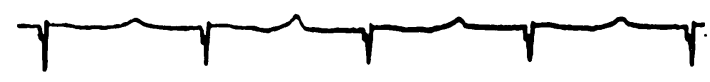

Lead II

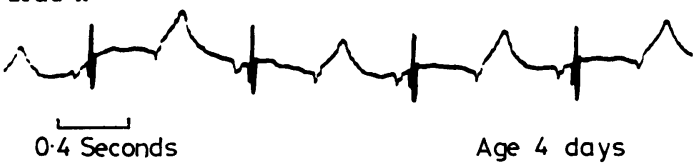

Fig. 1 Standard ECG showing a probable junctional rhythm of 130/min with $2: 1$ conduction and $a$ prolonged $Q T$ interval of 0.52 seconds $(Q T C=0.63)$. Origin of the impulse is probably junctional rather than sinus because of the abnormal $P$ wave axis $\left(-90^{\circ}\right)$.

cardia persisted until 9 days of age when the heart rate reverted to 130 /minute; no ECG was recorded at this time. The baby was discharged from hospital and 2 days later, while being breast fed, he collapsed and died. A post-mortem examination performed by the pathologist appointed to the Department of Health study group into SIDS failed to show an adequate cause for this death. The paediatricians who attended this infant before discharge from hospital were surprised by his death and did not consider that the transient postnatal bradycardia was responsible. A diagnosis of SIDS was therefore made by the coroner. Because of our interest in the possible association between neonatal arrhythmias and SIDS we were asked by the pathologist to review the ECG taken shortly after birth. Our interpretation was that this arrhythmia represented a probable junctional rhythm of $136 / \mathrm{min}$ with alternate junctional impulses failing to conduct to the ventricle because of the prolonged phase of repolarisation (a QT interval of 0.52 seconds as measured over 10 beats, QTC $=0.63$ ). A detailed study of the conducting system of the heart was normal. The sinus node was in the expected lateral position, and was morphologically normal. The posterior atrial ganglia were related to an area of epicardial haemorrhage, but contained no inflammatory changes. The atrioventricular node was well formed, and gave rise in normal fashion to a penetrating bundle. There were slight extensions of archipelagos into the central fibrous body. The branching bundle was well formed and the bundle branches of typical morphology. No inflammatory changes were noted in the conduction tissues.

There was no family history of deafness, fainting, or sudden death, and electrocardiograms on his parents and grandparents showed normal QT intervals.
Case 2

This girl was the first child of a 22-year-old nonsmoking, married woman who had emigrated to England from Pakistan 13 years previously. The mother was taking diazepam $2 \mathrm{mg}$ twice daily for anxiety during pregnancy and was investigated at 28 weeks' gestation for fainting attacks. At 32 weeks' gestation a fetal bradycardia of $90 / \mathrm{min}$ was noticed which persisted until the time of delivery. At 39 weeks, spontaneous onset of labour occurred and a term girl weighing $2.058 \mathrm{~kg}$ was born. A standard electrocardiogram on the first day of life showed sinus bradycardia of $90 / \mathrm{min}$ and as measured over 10 beats a prolonged QT interval of 0.52 seconds $(\mathrm{QTC}=0.54)$. Her serum calcium was $2 \cdot 34$ $\mathrm{mmol} / 1(9 \cdot 36 \mathrm{mg} / 100 \mathrm{ml})$ and potassium $4.8 \mathrm{mmol} / \mathrm{l}$. Subsequent electrocardiograms continued to show a long QT interval and a 24-hour electrocardiogram showed frequent ventricular premature beats (up to 40 per minute) (Fig. 2). Propranolol $1 \mathrm{mg} 8$ hourly was given and produced a pronounced reduction in the number of ventricular premature beats on the 24-hour ECG. The child is now 2 years but has a perceptive deafness. Her electrocardiogram continues to show a prolonged QT interval. She has remained well on propranolol and has never fainted. There was no family history of deafness or sudden death, and electrocardiograms on her parents have shown normal QT intervals.

\section{Discussion}

The prolonged QT interval found on the electrocardiogram in these two cases appears to represent congenital abnormalities of repolarisation. The presence of deafness in Case 2 indicates the Jervell and Lange-Nielsen syndrome (Jervell and LangeNielsen, 1957). Metabolic causes such as hypokalaemia, hypocalcaemia, and hypomagnaesaemia were unlikely to have been responsible for QT prolongation in Case 1 because the arrhythmia was present in utero.

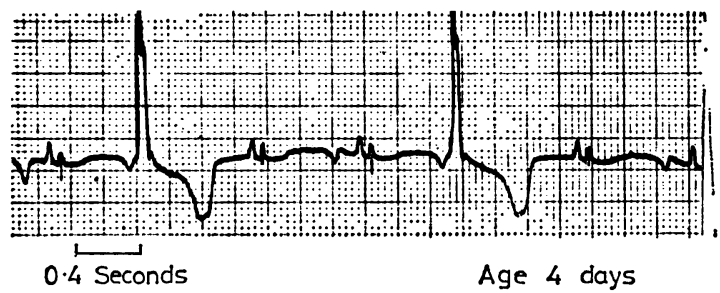

Fig. 2 24-hour ECG showing multiple ventricular premature beats and a prolonged $Q T$ interval of 0.52 seconds $(Q T C=0.54)$. (QRS tracings have been made darker). 
Experimental and clinical observations have suggested that the long QT syndrome may be due to a congenital disorder of the autonomic nervous system (Schwartz and Malliani, 1975; Schwartz et al., 1975). While a recent study by James et al. (1978) demonstrated inflammatory changes in the autonomic cardiac ganglia of patients with long QT, no such changes were present in our case. It is, however, interesting to note that both mothers were taking diazepam during pregnancy. This drug is known to affect the autonomic nervous system (Dukes, 1976).

Case 1 not only had a long QT interval but also a probable accelerated junctional rhythm with 2:1 conduction to the ventricle. We suspect a junctional rather than a sinus rhythm because of the abnormal $P$ wave axis $\left(-90^{\circ}\right)$ but an ectopic atrial focus is a possibility. We presume that alternate junctional beats failed to conduct to the ventricle because of its prolonged phase of repolarisation rather than atrioventricular node dysfunction, although we cannot exclude this latter conduction disorder. Conduction disorders probably representing sinus node dysfunction have previously been described by Olley and Fowler (1970) but to the best of our knowledge this particular arrhythmia has not been reported. An ECG was not performed when the heart rate was normal and therefore we do not know the mechanism behind this change in rate. The irregular rhythm noted before birth could have represented ventricular premature beats but none was documented on the standard ECG performed shortly after birth. In our opinion, a ventricular tachyarrhythmia associated with a low threshold for ventricular fibrillation due to the long QT interval was responsible for the sudden death of this infant, rather than asystole associated with the junctional rhythm and 2:1 atrioventricular conduction. We feel that the latter was secondary to the prolonged phase of repolarisation rather than to atrioventricular nodal dysfunction.

SIDS has been reported in siblings and other close relatives of children with the long QT syndrome (Romano et al., 1963; Fraser and Froggatt, 1964; Chaudron et al., 1976). Fraser and Froggatt (1964) and Schwartz (1976) suggested that some sudden unexpected infant deaths were likely to be associated with this conduction disorder. This hypothesis has however led to controversy. Maron et al. (1976) studied parents and siblings of cases of SIDS and found longer than normal QT intervals in some of these relatives. However, Kukolich et al. (1977) using similar family studies, and Kelly et al. (1977) in 'near-miss' SIDS cases, both failed to find significantly prolonged QT intervals. Smith (1978) has recently described a case of SIDS said to have had a prolonged QT interval of 0.32 seconds (QTC $=$ $0 \cdot 48$ ) on a perinatal ECG but in our opinion the QT interval on the published ECG was within the normal range (Walsh, 1963). Thus Case 1 in this present study provides strong evidence to support the hypothesis that there is a causal relationship between the long QT syndrome and some cases of SIDS. As previously suggested by Schwartz (1976) and Maron et al. (1976), only a prospective ECG study of a large newborn population will establish the true incidence of this conduction abnormality and determine the number of sudden infant deaths associated with it.

These cases are also of interest because they were detected before birth. Ventricular fibrillation or asystole in the fetus could result in an otherwise unexplained stillbirth and it is possible that a small number of stillbirths are related to the long QT syndrome.

Despite their arrhythmias both infants were clinically well at the time of their ECGs and in our opinion it is probable that their different outcomes related to the treatment of Case 2 with propranolol. This drug has been shown to reduce the severity and frequency of syncopal episodes in the long QT syndrome (Ward, 1964; Gale et al., 1970; Garza, et al., 1970; Wellens et al., 1972; Schwartz, 1976), possibly by reducing the incidence of ventricular tachyarrhythmias. 24-hour ECG monitoring of Case 2 showed that treatment with propranolol almost completely abolished ventricular extrasystoles.

The presence of a junctional rhythm in Case 1 might have represented an associated disorder of sinus node function. It is therefore possible that treatment with propranolol, because of its depression of automaticity and conduction (Stephen, 1966), could have precipitated dangerous bradycardias in this infant. However, a case has recently been described (Olley and Fowler, 1970), where, in this syndrome, syncope due to asystole and associated with short runs of slow junctional rhythm responded to propranolol.

The long QT syndrome is known to cause sudden death in older children. We suggest that our case of SIDS was probably due to an arrhythmia associated with this cardiac conduction abnormality. The absence of both a family history and of a prolonged QT interval in the relatives of these patients confirms that an obvious hereditary factor may not always be present. Only a large prospective study of the ECG in the newborn infant will establish the true incidence of this disorder.

We thank Dr Tain Forrest-Hay, who carried out the original post-mortem examination, for bringing Case 1 to our attention. Dr Southall is supported by 
a grant from the Board of Governors of the Brompton Hospital. We also thank Mrs Susan Cowley and Mrs Dorothy Lewis who typed the manuscript. The 24-hour analyser was supplied by the British Heart Foundation.

\section{References}

Chaudron, J. M., Heller, F., Van den Berghe, H. B., and Lebacq, E. G. (1976). Attacks of ventricular fibrillation and unconsciousness in a patient with prolonged QT interval. A family study. American Heart Journal, 91, 783-791.

Dukes, M. N. G., editor (1976). Meyler's Side Effects of Drugs, volume 8, p. 69. Excerpta Medica: Amsterdam.

Ferrer, P. L., Gelband, H., Garcia, O. L., Tamer, D. M., and Jesse, M. J. (1977). Occurrence of arrhythmias during the newborn period (abstract). Clinical Research, 25, 64A.

Fraser, G. R., and Froggatt, P. (1964). Letter: Congenital cardiac arrhythmia. Lancet, $2,648$.

Gale, G. E., Bosman, C. K., Tucker, R. B., and Barlow, J. B. (1970). Hereditary prolongation of QT interval. Study of two families. British Heart Journal, 32, 505-509.

Garza, L. A., Vick, R. L., Nora, J. J., and McNamara, D. G. (1970). Heritable QT prolongation without deafness. Circulation, 41, 39-48.

Guntheroth, W. G. (1977). Sudden infant death syndrome (crib death). American Heart Journal, 93, 783-793.

James, T. N., Froggatt, P., Atkinson, W. J., Jr, Lurie, P. R., McNamara, D. G., Miller, W. W., Schloss, G. T., Carroll, J. F., and North, R. L. (1978). De Subitaneis Moritbus. XXX. Observations on the pathophysiology of the long QT syndromes with special reference to the neuropathology of the heart. Circulation, 57, 1221-1231.

Jervell, A., and Lange-Nielsen, F. (1957). Congenital deaf-mutism, functional heart disease with prolongation of the QT interval, and sudden death. American Heart Journal, 54, 59-68.

Kelly, D. H., Shannon, D. C., and Liberthson, R. R. (1977). The role of the QT interval in the sudden infant death syndrome. Circulation, 55, 633-635.

Kukolich, M. K., Telsey, A., Ott, J., and Motulsky, A. G. (1977). Sudden infant death syndrome: normal QT interval on ECGs of relatives. Pediatrics, 60, 51-54.

Maron, B. J., Clark, C. E., Goldstein, R. E., and Epstein, S. E. (1976). Potential role of QT interval prolongation in sudden infant death syndrome. Circulation, 54, 423-430.
Morgan, B. C., and Guntheroth, W. G. (1965). Cardiac arrhythmias in normal newborn infants. Journal of Pediatrics, 67, 1199-1201.

Olley, P. M., and Fowler, R. S. (1970). The surdocardiac syndrome and therapeutic observations. British Heart Journal, 32, 467-471.

Radford, D. J., Izukawa, T., and Rowe, R. D. (1977). Evaluation of children with ventricular arrhythmias. Archives of Disease in Childhood, 52, 345-353.

Romano, C., Gemme, G., and Pongiglione, R. (1963). Aritime cardiache rare dell'età pediatrica. II. Accessi sincopali per fibrillazione ventricolare parossistica. Clinica pediatrica, 45, 656-683.

Schwartz, P. J. (1976). Cardiac sympathetic innervation and the sudden infant death syndrome. A possible pathogenetic link. American Journal of Medicine, 60, 167-172.

Schwartz, P. J., and Malliani, A. (1975). Electrical alteration of the $T$ wave: clinical and experimental evidence of its relationship with the sympathetic nervous system and with the long QT syndrome. American Heart Journal, 89, 45-50.

Schwartz, P. J., Periti, M., and Malliani, A. (1975). The long QT syndrome. American Heart Journal, 89, 378-390.

Smith, T. A. (1978). A case of sudden infant death. Resident and Staff Physician, 24, 54-55.

Southall, D. P., Vulliamy, D. G., Davies, M. J., Anderson, R. H., Shinebourne, E. A., and Johnson, A. M. (1976). A new look at the neonatal electrocardiogram. British Medical Journal, 2, 615-618.

Southall, D. P., Orrell, M. J., Talbot, J. F., Brinton, R. J., Vulliamy, D. G., Johnson, A. M., Keeton, B. R., Anderson, R. H., and Shinebourne, E. A. (1977). Study of cardiac arrhythmias and other forms of conduction abnormality in newborn infants. British Medical Journal, 2, 597-599.

Stephen, S. A. (1966). Unwanted effects of propranololdiscussion on side effects. American Journal of Cardiology, $18,463-472$.

Walsh, S. Z. (1963). ECG intervals during the first week of life. American Heart Journal, 66, 36-41.

Ward, O. C. (1964). A new familial cardiac syndrome in children. Journal of the Irish Medical Association, 54, 103-106.

Wellens, H. J., Vermeuler, A., and Durrer, D. (1972). Ventricular fibrillation occurring on arousal from sleep by auditory stimuli. Circulation, 46, 661-665.

Correspondence to Dr D. P. Southall, Cardiothoracic Institute, Brompton Hospital, London SW3 6HP.

Received 16 February 1979 